\title{
CAMBIAR DE SISTEMA ECONÓMICO: UN ASUNTO DE SUPERVIVENCIA
}

\section{ECONOMIC SYSTEM CHANGE: A MATTER OF SURVIVAL}

\author{
Anacristina Rossi*
}

RESUMEN

Este artículo da cuenta de un debate actual en Europa y Estados Unidos y Canadá: hemos topado con límites ecológicos planetarios más allá de los cuales la supervivencia de la especie no está asegurada. Se examinan dos textos claves en este debate, que plantean que dentro del sistema capitalista es imposible solucionar la crisis ecológica y por lo tanto es imposible la supervivencia. Se discuten las propuestas de los autores para salir de esta situación y se proponen otras visiones de cambio.

PALABRAS CLAVE: CAMBIO SOCIAL $*$ RECURSOS NATURALES $*$ BIOSFERA * SOCIALISMO

* CAPITALISMO $*$ CONTAMINACIÓN $*$ DESARROLLO SOSTENIBLE

\section{ABSTRACT}

This article introduces a debate currently taking place in Europe, USA and Canada: we are trespassing biogeochemical planetary boundaries beyond which human survival is not guaranted. The article examines two crucial texts that demonstrate that under the present capitalist system it is impossible to solve the ecological crisis and thus guarante human survival. The article discusses the ways out of this situation proposed by both texts, and based on their insights suggests other avenues for change.

KEY WORDS: SOCIAL CHANGE * NATURAL RESOURCES * BIOSPHERE * SOCIALISM * CAPITALISM $*$ POLLUTION $*$ SUSTAINABLE DEVELOPMENT

Escuela de Estudios Generales de la Universidad de Costa Rica. cristirossi@gmail.com 


\section{INTRODUCCIÓN}

Hay en estos momentos en Norteamérica $^{1}$ y Europa, entre sectores que podemos llamar de izquierda y progresistas - entendiendo progresistas en un sentido amplio, como aquellos que aspiran a una sociedad más justa - un debate al que creemos necesario prestar más atención. El debate se da porque el consenso científico indica que se están alcanzando límites planetarios en los sistemas biológicos y ciclos naturales que sostienen nuestra vida en la Tierra más allá de los cuales es posible que la humanidad no sobreviva (Paccalet, 2006), y la mayoría de las personas razonan que la ciencia y la tecnología actuales encontrarán la manera de salir del atolladero; sin embargo, ese razonamiento es erróneo. Este artículo se propone examinar dos textos cruciales en ese debate que muestran por qué dicho razonamiento es erróneo. Se trata de un artículo escrito en conjunto por John Bellamy Foster y Fred Magdoff —-What every environmentalist should know about capitalism", aparecido en la revista Monthly Review de marzo de 2010, y un libro de Jorge Riechman: Biomímesis. Ensayos sobre imitación de la naturaleza, ecosocialismo y autocontención, publicado en Madrid en 2006 por Libros de la Catarata.

Este artículo empieza exponiendo los planteamientos de estos autores respecto a la gravedad de la situación planetaria para luego discutir lo que consideramos la parte más importante de esos textos: la alternativa que proponen para salir de dicha situación —esta es la parte que podría llamarse utópica, si al contrario de lo que plantea Bertell Ollman (2005) entendemos por utópica la capacidad de pensar un futuro posible no sobre la base de deseos y sueños (Foster, 2005) sino fundándose en consideraciones científicas-; luego de una crítica a ciertos aspectos de esas visiones utópicas, aportaremos otra visión del futuro.

Todo autor es tributario de sesgos y preferencias conscientes o inconscientes que surgen de la cultura en que está inmerso. Hacer explícitas esas posiciones desde el 'principio de posicionamiento', como lo llama Bernal Herrera (2006)

$1 \quad$ Norteamérica incluye, para los efectos de este artículo, Estados Unidos y Canadá. en su artículo Cultura y contracultura: observaciones periféricas: “... la prioridad dada al concepto de posicionamiento debería obligar al analista a examinar la inserción real de sus propias prácticas cognitivas al interior de la formación cultural concreta en que actúa...". Los autores que discutimos en este ensayo pertenecen al mundo desarrollado del Norte y lógicamente son tributarios de esas culturas. Igualmente, son varones, $y$ a pesar de que no tienen una actitud falocentrista - Jorge Riechman por ejemplo, incluye específicamente la visión de género siempre que puede- estas dos características: la cultura en que están inmersos y su ser varón, marcan en cierta forma su trabajo.

Los tres autores parten de un análisis marxista, pero se centran en una problemática que el marxismo clásico no conoció: la destrucción de los sistemas que sostienen la vida. Es quizás ese aspecto nuevo y urgente lo que da a su pensamiento a la vez dirección y flexibilidad. Ambos afirman que, debido a la gravedad de la situación, de ahora en adelante todo pensamiento progresista debe tener como horizonte los límites de la ecosfera. Riechmann se dirige a las "gentes de izquierda" (2006: 337) para alentarlas a modificar sus análisis a partir de esos límites. Bellamy Foster y Magdoff, desde el título mismo de su artículo, llaman a los ambientalistas a ver no solamente los límites de la ecosfera sino también los del capitalismo.

En cuanto a este artículo, usar el concepto de posicionamiento implica indicar cuáles son los lugares desde los cuales escribimos. Tomando también el concepto de "situatedness" (Haraway, 1988) que, contra el sujeto desencarnado y abstracto de la razón clásica obliga a hacer explícita la posición del sujeto de enunciación y sus circunstancias, nos situamos como mujer ecologista y feminista centroamericana (Braidotti, 1994).

\section{RIECHMANN: ESTAMOS MINANDO LOS SISTEMAS DE SOPORTE DE LA VIDA}

Hoy día vivimos en un "mundo lleno". La noción es del economista Herman Daly ${ }^{2}$ y la retoma Riechmann:

2 Daly, Herman et ál. Para el bien común. México. FCE, 1993: 218, citado por Riechmann, 2006: 68. 
Habitamos hoy un planeta dominado por el ser humano en una escala que no admite parangón con ningún momento anterior del pasado. La humanidad extrae recursos de las fuentes de la biosfera $y$ deposita residuos $y$ contaminación en sus sumideros... Pero el crecimiento en el uso de recursos naturales y funciones de los ecosistemas está alterando la Tierra globalmente, hasta llegar incluso a trastocar los grandes ciclos biogeoquímicos del planeta: la circulación del nitrógeno o el almacenamiento del carbono en la atmósfera, por ejemplo (2006:44).

En efecto, en un mundo que no conoce más límites a la producción que los del desarrollo tecnológico, el metabolismo entre la sociedad y la naturaleza, necesariamente se trastoca. Extraemos de esta demasiado y demasiado rápido para que pueda regenerarse, y saturamos su capacidad de asimilar nuestros desechos, sin darnos cuenta de que nuestra vida depende de los servicios ambientales que los ecosistemas nos dan: aire, agua, salud, alimentos, un clima relativamente benigno, etc. Riechmann cita a Hawken, Lovins y Lovins:

Aun cuando los sistemas vivos son la fuente de materiales tan deseados como la madera, el pescado u otros alimentos, los servicios que ellos ofrecen son de la máxima importancia y resultan mucho más decisivos para la prosperidad humana que los recursos no renovables. Un bosque no sólo proporciona el recurso de la madera sino también los servicios de almacenamiento de agua $y$ control de inundaciones. Un ambiente sano aporta en forma automática no sólo agua y aire limpios, lluvia, productividad oceánica, suelo fértil y cuencas fluviales resilientes, sino también otras funciones menos apreciadas como el procesamiento de desechos (tanto naturales como industriales), la amortiguación contra los extremos del clima, la regeneración de la atmósfera, etc. (2006:66).
El informe de la Evaluación de los Sistemas del Milenio, auspiciada por la ONU y elaborado por 1300 expertos de 95 países, publicado en 2005 , concluye que "dos terceras partes de los ecosistemas de los que depende la vida en la Tierra están sobreexplotados o se utilizan de manera insostenible, lo que podría traer consecuencias desastrosas para la humanidad en las próximas décadas" (Riechman, 2006: 64).

Si los ecosistemas que nos dan los servicios ambientales de los cuales depende nuestra vida están sobreexplotados o utilizados de manera insostenible, porque extraemos de ellos demasiado y demasiado rápido y no les damos tiempo de regenerarse, la única solución es dejar de sobreexplotarlos, lo que significa dejar de producir como se produce hoy: sin más límites que los del desarrollo tecnológico. Riechmann define el crecimiento material de la economía como "el flujo de materiales y energía que atraviesa el sistema productivo, donde es elaborado para dar origen a bienes y servicios útiles y genera, como indeseable subproducto: contaminación y pérdida de calidad ambiental" (2006: 98). El problema del crecimiento es que, como lo señala la economía ecológica en contraposición a las ilusiones de la economía convencional, toda producción entraña destrucción. Si la destrucción al producir bienes $y$ servicios es inevitable, $y$ si estamos llevando los ecosistemas a un límite más allá del cuál ya no podrán sostener la vida, hay que detener el crecimiento material de la economía (2006:99) y pensar muy bien qué, cuánto y cómo se produce. Por eso Riechmann afirma que el futuro será de autolimitación o no será.

Riechman aclara que son los países desarrollados los que deben autolimitarse, primero, pues son los que con su desarrollo han usurpado el espacio y la capacidad para desarrollarse de los demás países: “... el Norte tiene que decrecer - dejando libre espacio ambientalpara que el Sur pueda crecer" (2006: 98). Sin embargo, y esto Riechman no lo menciona, no se trata de crecer de la misma forma en que han crecido los países hoy desarrollados pues si así fuera y siendo subdesarrollada más de la mitad de la Tierra, estaríamos empeorando la situación. 
BELLAMY FOSTER Y MAGDOFF: NO HAY CAPITALISMO VERDE

Estos dos autores están de acuerdo con el consenso científico que indica que "continuar como vamos nos lleva al desastre global" (2010: 5). Para detener ese desastre "necesitamos que las economías -en particular las de los países ricos- no crezcan" (2010: 5-6). En efecto, el Worldwatch Institue recientemente estimó que un mundo que usara la biocapacidad per cápita como la usa actualmente EEUU, sólo podría sustentar 1400 millones de personas sobre el planeta - compárese con los siete mil que somos actualmente o con los nueve mil que seremos para 2050-. Para estos autores el problema no lo causa aquella parte de la humanidad que vive con menos de $\$ 2,50$ diarios, sino aquellos para quienes "suficiente" es poco (2010: 6).

Pero según Bellamy Foster y Magdoff, hay que quitarse las ilusiones que tienen muchos ecologistas de un "capitalismo verde", porque la destrucción ecológica está en la naturaleza interna y en la lógica del capitalismo. No resolveremos los graves problemas ecológicos que amenazan nuestra supervivencia mientras no sanemos el enfermo metabolismo sociedad naturaleza, $y$ para eso hay que cambiar el modo en que se toman las decisiones sobre cuánto producir, qué y cómo producirlo. El problema es que esto el capitalismo no lo permite. En efecto, las características esenciales del capitalismo son antagónicas a la autolimitación que exige la protección de los sistemas que garantizan nuestra supervivencia (2010: 8). ¿Cuáles son esas características según los autores?

En primer lugar, el capitalismo no puede dejar de crecer (2010: 8). Cuando el crecimiento cesa, el sistema entra en crisis, causando desempleo y un enorme sufrimiento a las personas. La razón de ser del capitalismo, su fuerza impulsora, es amasar riqueza mediante el proceso de acumulación - ahorro e inversión-. Nuestro medio ambiente es una biosfera finita, dicen los autores, un espacio limitado en el que debemos coexistir con otras especies. Pero el capitalismo lo considera un espacio ilimitado para explotarlo en un proceso de creciente expansión económica. Las empresas y los negocios, de acuerdo con la lógica interna del capital - puesta en marcha por la competencia- deben crecer o morir, igual que el sistema mismo. Las ganancias no aumentan si no hay crecimiento o si el crecimiento es lento. Es verdad que el sistema puede seguir adelante hasta cierto punto, nos dicen los autores, impulsado por la especulación financiera apoyada en un endeudamiento cada vez mayor, y esto es lo que estamos viendo desde los años setenta. Pero esto significa, como también lo hemos visto una y otra vez, la creación y posterior explosión de burbujas financieras. En realidad, en el capitalismo no hay alternativa a la expansión sin fin de la economía "real", es decir, de la producción material, sean cuales sean las necesidades humanas reales $y$ las limitaciones del medio ambiente.

Claro que, en teoría, una economía capitalista puede tener crecimiento cero y aún así satisfacer todas las necesidades básicas de la humanidad (2010: 9). Supongamos que los capitalistas gastan todas las ganancias de sus empresas (después de remplazar los bienes de capital deteriorados) en su propio consumo o las dan a los trabajadores como salarios y beneficios, $y$ estos a su vez las gastan. Al gastar esas ganancias, compran los bienes y servicios producidos, $y$ la economía puede entonces permanecer en un estado estable sin crecimiento, lo que Marx llamó "reproducción simple" y John Stuart Mill "estado estacionario". Como no habría inversión en nueva capacidad productiva, no habría crecimiento económico ni acumulación. Pero hay un pequeño problema con esta "utopía de crecimiento cero capitalista", nos dicen los autores (2010: 9), y es que se opone a la fuerza motriz del capitalismo. En efecto, su razón de existir y su objetivo último es la expansión. Difícil imaginar a un capitalista, que vive para acumular riqueza, renunciando a la expansión de sus empresas y gastando sus ganancias o repartiéndolas a sus trabajadores. Al contrario, es claro que los capitalistas harán siempre todo lo posible para maximizar la acumulación de utilidades. Por lo tanto, una economía de crecimiento cero sólo es posible imaginarla separada de las relaciones sociales del capital (2010: 9). 
En segundo lugar, el capitalismo es un sistema que genera un ejército laboral de reserva (2010: 9); por ello, el pleno empleo es una rareza que se da solamente cuando hay tasas muy altas de crecimiento — que a su vez son un peligro para la sostenibilidad ecológica-. La economía capitalista debe crecer, y bastante, para no generar dolor y sufrimiento a los trabajadores. En EEUU, por ejemplo, cuando el crecimiento del PIB no es sustancialmente mayor que el aumento poblacional, se empiezan a perder los empleos (2010: 11).

Además, la lógica de la expansión inherente al capitalismo lleva a invertir afuera para aprovechar materias primas, mano de obra barata $y$ nuevos mercados. En estos momentos, estamos en medio de una nueva rapiña de tierras, dicen los autores (2010: 11) y es fácil comprobarlo: los países árabes del golfo, muchos países desarrollados — los autores no lo mencionan pero nosotros agregamos a la China, con su capitalismo de estado-y las corporaciones transnacionales están comprando enormes cantidades de tierra por ejemplo en África, para producir comida y materias primas de biocombustibles para sus propios mercados. Esta rapiña global de tierras — si bien "legal"es parte de la historia del imperialismo - como el "scramble for Africa" del siglo XIX, agregamos nosotros-. Las guerras estadounidenses contra Irak y Afganistán responden al mismo movimiento: controlar fuentes importantes de petróleo y gas (2010: 11). Hoy día, conforme las corporaciones transnacionales arrasan el mundo en busca de recursos y oportunidades, el resultado va siendo una explotación global de la naturaleza absolutamente rapaz y despiadada, pues a las corporaciones sólo les importan sus ganancias en el corto plazo. Y aquí los autores llegan a la misma conclusión que Riechman: como toda producción entraña destrucción, es imperativo cambiar la manera en que se toman las decisiones sobre qué producir, cuánto y cómo producirlo. El problema es que en el sistema capitalista actual no hay ninguna manera racional de establecer prioridades, nos dicen los autores (2010: 13). Las empresas, usando su poder económico, toman decisiones y asignan recursos solamente en función del mercado. Nadie protege el interés común, los sistemas de los cuales depende la vida, los recursos colectivos: aire, agua, clima, pesquerías, humedales, bosques, mares, biodiversidad. La situación sería muy diferente si las comunidades administraran ellas mismas los recursos de los cuales depende su bienestar (2010: 13).

El planeta Tierra puede verse como un conjunto de procesos biogeoquímicos que, por cientos de millones de años, han servido para reproducir la vida (2010: 14). Ahora, sin embargo, los principales ciclos han sido perturbados: el del carbono, el del nitrógeno, los de los suelos, de los bosques, de los océanos. Todos los ecosistemas de la tierra están en decadencia (2010: 14). Al aumentar año con año la escala de la economía mundial, estas heridas generadas por los humanos en el metabolismo de la Tierra serán cada vez más diversas y severas. Y sin embargo, es imposible detener este proceso porque la exigencia de más y más crecimiento económico y más y más acumulación es, como ya vimos, inherente al capitalismo mismo. Además, el capitalismo no es solamente un sistema económico, sino que tiene un sistema político, jurídico y social que apoya y patrocina el sistema de acumulación de riqueza y poder (2010: 15). Las personas están al servicio de la economía, y para que la economía siga creciendo y no haya crisis ni desempleo, deben consumir cada vez más en una loca y absurda carrera hacia delante. Ahora queda claro por qué el título de nuestro ensayo parafrasea a Bellamy Foster cuando dice que "conocer la naturaleza y los límites del capitalismo para trascenderlo es un asunto de supervivencia" (2010: 1). No hay absolutamente nada, dentro del sistema actual, que permita cambiar antes de que sea demasiado tarde. "Para cambiar se requerirán otras fuerzas, no precisamente las que están en la parte de arriba de la sociedad", nos dicen los autores (2010:15).

\section{RIECHMANN: ¿UNA SOCIEDAD ECOLÓGICAMENTE SUSTENTABLE AL ALCANCE DE LA MANO?}

Si dentro del capitalismo no hay alternativa a la destrucción de los ecosistemas que 
sustentan la vida en el planeta, ¿cuál es la salida? En un libro de 360 páginas, Riechmann, nos lleva paso por paso al mundo del futuro. Trataremos de hacerle justicia en este breve espacio a su propuesta, que nos parece sólida, hermosa y realista.

En primer lugar, para resolver el problema ecológico, que es el de la supervivencia, debe cesar la guerra entre la tecnosfera - todo lo creado por los seres humanos-y la biosfera. ¿Cómo? Basándonos en las pp. 233-255 hemos retomado la propuesta de Riechmann en los once principios que nos parecen fundamentales. Los seis primeros tienen que ver con la biomímesis o imitación de la naturaleza, aspecto crucial de su visión. Se trata de rediseñar la tecnosfera imitando la naturaleza, no porque la naturaleza sea "moralmente buena" sino "porque funciona, porque tiene más tiempo de rodaje" (2006: 215). Veamos:

1. No debe haber crecimiento material de la economía. Se debe reducir el consumo de recursos naturales per cápita a un nivel que le permita a la naturaleza regenerarse para poder seguir dando servicios ambientales y asimilar la contaminación.

2. Vivir del sol como fuente energética. Una civilización solar no tendría el dinamismo expansivo de los combustibles fósiles, y sólo resultaría coherente con una economía en "estado estacionario" y con un ethos de la autolimitación.

3. Cerrar los ciclos de materiales. Una economía ecologizada distinguiría dos tipos de metabolismo: a) todo lo que fuera a parar al metabolismo biológico de la naturaleza sería perfectamente biodegradable y no contendría ningún tóxico, b) todo lo que fuera al metabolismo industrial circularía una y otra vez en ciclos cerrados, sin mezclarse con el metabolismo biológico. El planteamiento es residuo cero: todos los residuos de los procesos productivos deben ser aprovechados como materia prima, igual que sucede en los ciclos de materiales de la biosfera.

4. Evitar los xenobióticos como los COP (contaminantes orgánicos persistentes) y los transgénicos, es decir, lo que es extraño a los sistemas naturales.

5. Respetar la diversidad. La diversidad —de genes, de organismos, de poblaciones, de ecosistemas, etc.- es la característica de la biosfera. Respetar pues las singularidades regionales, culturales, materiales y ecológicas de los lugares.

6. Un ethos de autocontención, autolimitación y justa medida.

7. No llenarlo todo. Dejar suficiente espacio ambiental para los demás según el principio de "mitad y mitad", es decir, el 50\% del espacio ambiental disponible para la humanidad, el otro $50 \%$ para los seres vivos no humanos.

8. Aumentar la ecoeficiencia. Más bienestar humano con menos insumos de energía $y$ materiales.

9. Solidaridad entre todas las poblaciones del mundo y entre las generaciones actuales $y$ futuras.

10. Una democracia intensificada, de mucha mayor participación.

11. Una estrategia de reducción de las desigualdades sociales. Redistribuir el ingreso y plantear la cuestión de la propiedad.

Riechmann acepta que esta propuesta requiere una reorientación radical de las prioridades de inversión y el control social sobre las actividades económicas, y esto afecta el "meollo" del poder capitalista: el control privado sobre las decisiones de inversión económica. "Por lo tanto", nos dice, "no hay posible solución de la crisis ecológica global sin una política económica ecosocialista, y esto supone enfrentarse con el poder del capital" (2006: 294). Menudo problema. La propuesta es hermosa, científica, sensata y necesaria pero Riechman nos advierte que topa con una barrera casi infranqueable: el poder del capital. En el párrafo que sigue, Riechmann, en lugar de sugerir cómo enfrentar el poder del capital, nos dice que si en algún grupo de naciones del planeta pudiera avanzarse hacia un ecocapitalismo y luego hacia un ecosocialismo, sería en la Unión Europea (2006: 294). Nosotros no vemos ninguna razón para ese optimismo. Pero sigamos. Riechmann explica su ecosocialismo: 
Un modelo de producción ecosocialista implicaría pasar de la actividad económica entendida como producción y consumo de bienes y servicios en un contexto de expansión mercantil a la actividad económica entendida como satisfacción de las necesidades humanas con el mínimo de trabajo social necesario $y$ en un marco de sustentabilidad ecológica (2006: 263).

Riechmann acepta que este es un cambio de modelo para el cual se necesita una "revolución cultural en el ámbito de los valores y los deseos" (2006: 264). ¡Otro menudo problema! El mismo al que se enfrentaron los movimientos revolucionarios latinoamericanos hace décadas y al que se daba como solución "forjar el hombre (sic) nuevo", sin especificar cómo se lograba esta transformación más allá de que el cambio en la infraestructura traería el cambio de la superestructura. El autor está consciente de que el ecosocialismo, la ecología política, es el saber de los límites impuestos al desarrollo humano por la finitud de la biosfera, e "implica la necesidad de transformar la política entera y por lo tanto también la política socialista, comunista y anarquista" (2006: 288). Esto implica transformar radicalmente el comunismo y el socialismo conocidos hasta hoy. Es preciso desechar, por ejemplo, el postulado del crecimiento ilimitado de las fuerzas productivas como antesala de una sociedad socialista. O saber -y la noción es del comunista Manuel Sacristán- que las fuerzas productivas son "productivo-destructivas" (2006: 288). También se debe cuestionar el concepto de progreso, $y$ la cultura productivista generada por el capitalismo. El ecosocialismo debe tomar nota del fracaso del socialismo real y de la socialdemocracia europea y denunciar la falsedad de la tesis de la abundancia, central para los modelos clásicos del socialismo (2006: 289). Esto requiere una verdadera revolución cultural dentro del movimiento obrero y de las clases trabajadoras en general (2006: 290), algo muy difícil pues como lo señala Albert Recio citado por Riechman (2006: 269-70 y 270), “... en parte la expansión del consumismo debe ser considerada una respuesta igualitaria de una porción creciente de la sociedad que exige tener los mismos derechos, no sólo políticos, que las clases privilegiadas". La única sugerencia que ofrece Riechmann para lo más difícil, la "revolución de los valores y los deseos", la "conversión espiritual" (2006: 141) que nos desenganche del consumismo — por más igualitario - es voltearnos hacia la filosofía de Epicuro. Y Epicuro es muy problemático para las mujeres.

\section{PROBLEMÁTICO EPICURO}

Desde Marx, los filósofos materialistas han puesto atención a Epicuro (301-270 a.c.), $y$ es indudable que para el pensamiento ecologista y revolucionario hay un aspecto de su filosofía que es muy atractivo: lo que podemos llamar su ética de la autocontención: "Nada es suficiente para quien suficiente es poco", nos dice (Epicurus, 1964: 71). Este aspecto de la autolimitación como vía para llegar a la felicidad, esta deseable capacidad de discernir entre lo necesario y lo superfluo, se acompaña de un rechazo a la lucha competitiva, a la acumulación de riquezas, que resulta muy rico para el pensamiento anticapitalista "Querer dinero injustamente ganado es impío; querer dinero justamente ganado es indecoroso; es vergonzoso atesorar con sordidez, incluso de acuerdo con lo que es justo" (Epicurus, 1964: 69).

Sin embargo, inspirarse en Epicuro más allá de su concepto de autolimitación resulta problemático para las mujeres, porque su filosofía no trasciende la misoginia de la antigüedad griega. Se ha dicho que Epicuro sustituye la comunidad política por la comunidad de amigos, $y$ que las sociedades de amigos epicúreas fueron excepcionales por la lealtad que caracterizaba a sus miembros, $y$ numerosas $y$ muy estables a lo largo de toda la antigüedad. No tenemos razones para dudar de que así haya sido, pero debemos señalar que estas eran comunidades de varones. Las mujeres griegas estaban generalmente excluidas de la política y de la vida pública, de los banquetes, de la educación (Cantarella, 1991). Por lo tanto, y salvo contadas excepciones, no eran interlocutoras válidas para los varones filosofantes. Sólo lo 
eran las hetairas, es decir, las prostitutas, que sí se cultivaban, participaban en las discusiones filosóficas, asistían a los banquetes, etc. Esta vida misógina se reproduce en el Jardín: tenemos noticia de solamente tres mujeres epicúreas, de las cuales dos eran hetairas y una la esposa de uno de los varones miembros.

Quizá los problemas empiezan con la concepción epicúrea del amor: el amor no es más que "un apetito vehemente de placeres sexuales, acompañado de furor y angustias" (García et ál., 1974: 242). Para Epicuro hay amor pasión (erós) y deleite sexual (ta aphrodisia) (García et ál., 1974). Aconsejaba rechazar erós y satisfacer ta aphrodisia: "Las relaciones sexuales, dicen, nunca producen provecho, pero son amables con tal que no produzcan daño" (García et ál., 1974: 137). Es decir: relaciones sexuales sí pero amor no. Y nos dice cómo deshacerse del amor: "Si se suprime la vista, el trato y el contacto frecuente, se desvanece la pasión amorosa" (Epicurus, 1964: 67). Esta moral de amor no y relaciones sexuales sí -mientras sean superficiales y no dejen huella, es decir, mientras no creen vínculo-, es la que lleva a Lucrecio, máximo exponente de las teorías epicúreas, a decir que hay que defenderse del amor mediante la promiscuidad:

Conviene evitar lo que da pábulo al amor $y$ volver la mente a otras ideas: descargar el líquido acumulado contra un cuerpo cualquiera, antes que retenerlo y guardarlo para un único amor, y procurarse así cuitas e inevitable dolor" (IV, 10641067, citado por García et ál., 1974: 244).

Es imposible imaginar a una griega o romana de la antigüedad, mujeres controladas $y$ vigiladas si alguna vez las hubo, ejerciendo la promiscuidad. En Grecia esto podían hacerlo sólo las hetairas. ¿Debían entonces todas las mujeres epicúreas ser prostitutas?

\section{PITÁGORAS}

Pensamos que si fuese necesario inspirarse a toda costa en la antigüedad clásica para un cambio de modelo, llámese este nuevo modelo ecosocialismo, socialismo ecológico, comunismo o ecocomunalismo (Bellamy, 2005), puede ser mucho más satisfactorio inspirarse en Pitágoras (582-507 a.c.) el único pensador de la antigüedad que logró trascender la misoginia griega. Además de ser el primero en fundar comunidades unidas por principios filosóficos, exigía una perfecta igualdad entre hombres y mujeres (Lambropoulou, 1995: 122). Esto es inaudito en el mundo antiguo. Jámblico (Iamblichus, 1989) reporta 17 filósofas pitagóricas, lo que es mucho si se tiene en cuenta el voto de secreto que se exigía a las y los pitagóricos y que se hizo más fuerte a partir de su persecución en el siglo v. De las pitagóricas, nos han llegado fragmentos de las obras de Perictione, Melissa, Lysys, Damo, Fintis, Aesara, Myia, Bistala y Téano, mientras que de las epicúreas sólo tenemos noticia de los trabajos de Leoncion, una prostituta, que Cicerón elogia.

Desde el punto de vista social, los principios pitagóricos son mucho más satisfactorios que los epicúreos. No solamente postulaban una completa igualdad entre hombres y mujeres, tampoco hacían distinción entre clases sociales ni entre esclavos y personas libres (Lambropoulou, 1995: 126). Además, así como podríamos decir que los Pitagóricos fueron los primeros feministas de Occidente, también podemos decir que fueron los primeros comunistas: Pitágoras "erradicó todo egoísmo de carácter y extendió el sentido de comunidad hasta las últimas posesiones, aquellas que causan facciones $y$ rupturas. Todas las cosas se tenían en común y eran las mismas para todos: no había propiedad privada" (Iamblicus, 1989: 75). También los pitagóricos fueron los primeros pacifistas: "Es mejor ser herido que matar a un ser humano" (1989: 79), lo cual asombra entre culturas tan guerreristas como la griega o la romana. Pero lo más importante para una ética ecologista es que Pitágoras insistió como nadie en la antigüedad grecorromana en la íntima conexión que existe entre todos y todo sobre la Tierra; postuló que humanos y animales somos hermanos, al punto de prohibir los sacrificios de animales y exigir el vegetarianismo entre sus seguidores (Iamblicus, I989: 75). 
EL SOCIALISMO ECOLÓGICO DE BELLAMY FOSTER Y MAGDOFF

Estos autores también imaginan cómo podría o debería ser una sociedad que permita a los humanos sobrevivir, $y$ si bien la elaboran mucho menos que Riechman, los tres autores coinciden en los aspectos fundamentales. Todos los argumentos del artículo de Bellamy Foster y Magdoff van a demostrar que la crisis ecológica no puede ser resuelta dentro de la lógica del capitalismo.

El nuevo sistema sostenible deberá ser razonablemente igualitario, mucho más democrático que lo que ahora conocemos y capaz de ponerle límites a la producción y al consumo para que sea ecológicamente sostenible. La nueva sociedad deberá ser socialista: "Los objetivos del socialismo y de la ecología necesariamente deberán unirse" (2010: 25). "Pero", afirman, "la transición a una economía ecológica será una cuesta empinada y no ocurrirá de la noche a la mañana” (2010: 24). Un punto que nos parece importante es que para estos autores, en el nuevo sistema sostenible el ambiente no se considerará algo externo a la economía, como la actual ideología nos ha acostumbrado, sino que el ambiente se verá como lo que es: el sistema que permite la vida de todas las criaturas. Para restablecer un metabolismo sano entre la sociedad humana y la naturaleza, el estilo de vida consumista y dispendioso de la "clase media" de los países desarrollados, deberá descartarse; habrá que crear nuevas maneras de vivir, producir, cosechar, transportar. Y aquí los autores se enfrentan con las mismas dificultades que Riechmann: ¿cómo lograr este cambio? No lo resuelven, pero quizás lo abordan de un modo más satisfactorio. Sugieren que este cambio en el modo de vivir de las personas se irá imponiendo por la sencilla razón de que conforme la crisis ecológica avance se irá viendo que no hay otra alternativa si la especie quiere sobrevivir.

Estamos de acuerdo con estos dos autores. Sostenemos que la realidad parece indicar que los cambios hacia una sociedad sostenible o ecosocialista no se darán por ningún voluntarismo político; no se darán según las "ocho tesis" de Riechmann (2006: 293) ni gracias a un esfuerzo "pedagógico y político de ilustración socioecológica" (2006: 294) de las masas. Los cambios se darán forzados por las dificultades cada vez mayores que tendrán los ecosistemas para darnos los servicios que sostienen la vida, o no se darán.

\section{OTRA VISIÓN: PARTIENDO DE LOS INTERSTICIOS}

Es también posible que los cambios propuestos por los tres autores no se lleguen a dar y que ante la crisis ecológica el mundo se sumerja en la barbarie, en una ruptura total de la socialidad o en una encarnizada lucha a muerte por los pocos recursos y servicios ambientales que vayan quedando. Esos son justamente los escenarios de "barbarie" del Global Scenario Group, un proyecto del Instituto Ambiental de Estocolmo en su informe Great Transitions: Colapso, y Mundo de Plazas Fuertes (Bellamy, 2005: 4). Pero, al menos como opción metodológica, nosotros adoptaremos una actitud pascaliana siguiendo a Riechman (2006: 359) y supondremos que la humanidad escogerá la vida.

A pesar de que Bellamy y Magdoff van un paso más allá que Riechman al señalar - acertadamente, creemos - las razones por las cuales el cambio vendrá, y la dirección de donde vendrá, finalmente topan con un problema similar al de Riechmann. En efecto, nos dicen que conforme la vida se vuelva más insostenible se irá haciendo más evidente que la comida, la salud, la vivienda, etc. deberán asignarse según las necesidades humanas y no las fuerzas de mercado (2010: 25). Sí, se puede estar de acuerdo con los autores en que en un escenario de crisis creciente de los sistemas de soporte de la vida, esto se irá haciendo cada vez más evidente; pero creemos que no por eso las personas que tienen el poder y el control de la economía van a querer renunciar a la asignación de recursos mediante el mercado. Aquí topamos de nuevo con lo que plantea Riechman (2010: 294): que tomar el control social de las actividades económicas y reorientar las prioridades de inversión implica enfrentarse al poder del capital. Estamos de acuerdo con ese planteamiento 
$y$ creemos que cuando llegue ese momento, si llega, todo dependerá del balance de fuerzas existente, como dice el mismo Riechman (2010: 94). Pero nos parece que para que ese balance de fuerzas sea favorable a la construcción de una sociedad sustentable y justa no basta con haber sabido realizar "nuestro trabajo pedagógico y político de "ilustración socioecológica" (2006: 294); no: algo tiene que haber debilitado antes el sistema del capital.

¿Qué puede debilitar la fuerza y el control del sistema capitalista?

Nos parece que la pista nos las dan Bellamy y Magdoff. En efecto, ellos señalan en forma muy marxista y dialéctica aquello del presente que contiene las semillas del futuro (Ollman, 2005). Dicen que hay que escuchar lo que está creciendo en los intersticios de la sociedad porque es allí donde están naciendo los gérmenes de una sociedad nueva, así como "de los poros de la sociedad feudal nació la burguesía” (Bellamy y Magdoff, 2010: 25). Estos movimientos de los intersticios están en todo lado, nos dicen. Son los grupos indígenas de Bolivia que plantean una relación ética con la Tierra, la Pacha Mama; es la Vía Campesina; es el Movimiento de los Trabajadores sin Tierra de Brasil; son los movimientos ecologistas y antiglobalización alrededor del mundo, etc. Todos estos grupos quieren nuevas relaciones entre las personas y con la naturaleza y se oponen a la lógica del capital.

Nos parece acertada la visión de estos dos autores de que el futuro está creciendo en los intersticios de la sociedad actual. La fuerza de los movimientos campesinos y sus valores ligados a la tierra, así como los valores ancestrales de los indígenas de Norte y Suramérica son definitivamente los insumos necesarios para la construcción de una sociedad sostenible, como lo son también los valores de los altermundialistas, de los activistas antiglobalización, y de todos los movimientos contestatarios alrededor del mundo que señalan los autores.

\section{LOS INTERSTICIOS DE NORTEAMÉRICA}

Curiosamente Bellamy y Magdoff solamente valoran los intersticios fuera de su país, y no le dan importancia a algo que puede ser clave como transición y semilla de la sociedad futura. Ese algo son los movimientos en los intersticios que se están dando en Estados Unidos y Canadá. No se trata solamente de movimientos ecologistas, si bien todos estos movimientos, sin excepción, propugnan una relación armoniosa con la naturaleza. Está fuera de los alcances de este artículo abundar en los detalles de cada uno de estos grupos sociales, pero cualquiera que mire con un ojo atento lo que está pasando en Estados Unidos y Canadá constatará la fuerza y la importancia que tienen. Estos movimientos son: los intentional communities, las eco-villages, los movimientos de agricultura urbana y de agricultura orgánica, los movimientos de recuperación de tierras y paisajes públicos para las comunidades, los movimientos de permacultura, de comunicación no violenta, los proyectos comerciales colectivos y alternativos, los movimientos de sencillez voluntaria y muchísimos otros. Basta con leer un libro como The great remembering (Forbes, 2001) o Stepping Lightly (Burch, 2000) para darse cuenta de que en cada barrio suburbano, en cada ciudad próspera o decadente, en cada localidad rural hay personas que rechazan lo que solía llamarse "el modo de vida americano (sic)" de consumo, individualismo y apariencias. Como lo dice Grace Le Boggs en una columna de Amy Goodman (2010) refiriéndose a los grupos sociales de Detroit, estos "son ahora símbolo de una nueva sociedad, de gente que cultiva sus propios alimentos, de gente que intenta ayudarse entre sí, de gente que comienza a pensar no tanto en conseguir empleos y amasar riquezas sino en las formas en que nos necesitamos unos a otros...". Según Goodman, y estamos de acuerdo con ella, son nuevas opciones de vida basadas en la autosuficiencia, en la agricultura comunitaria, en el trueque, en la solidaridad. Para decirlo de otro modo, son opciones de vida que rechazan lo que Bellamy y Magdoff llaman la lógica del capital.

El ánimo que mueve estos movimientos norteamericanos no es nuevo, todo lo contrario. Los pitagóricos, los estoicos, los cínicos y los epicúreos sin saberlo practicaban 
la sencillez voluntaria, la autosuficiencia $y$ la solidaridad. En el Tercer Mundo hay muchísimos grupos y personas que se oponen a la lógica del capital: los grupos indígenas que reclaman valores ancestrales de respeto a la Tierra — pensemos en los indígenas Bribri aquí en Costa Rica que nunca han permitido que se construyan puentes sobre sus ríos portentosos, para evitar que el "progreso" entre y arrase con sus recursos naturales-, los grupos ecologistas, las personas que prefieren un trabajo modestamente remunerado pero que los satisface a un trabajo extenuante y vacío pero bien pagado, en fin, todas las personas, familias $y$ grupos que por diferentes razones no han querido y no quieren entrar de lleno en el modo de vida del consumismo globalizado.

Lo que es nuevo en estos movimientos de Norteamérica es que, estando en el corazón mismo del capitalismo desarrollado, en sus bastiones ideológicos, su fuerza y su número sean crecientes. Eso apunta a una gran insatisfacción con el sistema y a un cuestionamiento importante del capitalismo desde adentro, y no como se había dado hasta ahora, desde la periferia. En Latinoamérica los intentos por cambiar el sistema capitalista —El Chile de Allende, El Salvador de los territorios liberados, la Guatemala de Arbenz- fueron aplastados porque es fácil para la metrópolis desplegar todo su poderío en la débil periferia. Es diferente lidiar con un cuestionamiento que surge con fuerza desde adentro.

En el mundo desarrollado, como salida a la crisis ecológica y como vía para lograr el famoso cambio en los valores del que habla Riechman, - un cambio ideológico- estos movimientos podrían ser uno de los caminos más interesantes. Si en Estados Unidos y Canadá continúan creciendo, pueden llegar a tener efectos sensibles, por tres razones.

La primera es que estos grupos tienen un común denominador: una reducción considerable $y$ deliberada del consumo, $y$ esto es un cambio a la vez material e ideológico. Por ejemplo, entre las principales características de los movimientos de la sencillez voluntaria tenemos:
Autosuficiencia, minimalismo, reducción deliberada del consumo, reducción deliberada de las posesiones materiales; redirigir de modo consciente las decisiones de consumo a favor de formas más sostenibles de transporte, vivienda, diversión y producción de alimentos (Burch, 2000: 11-21).

Como lo señalan Bellamy y Magdoff y como hemos visto a tenor de la reciente crisis económica y financiera, la reducción del consumo hace tambalearse materialmente al sistema capitalista. Y nosotros pensamos que de constituirse en una tendencia firme, hace tambalearse la ideología del capitalismo, la cual dice que hay que consumir cada vez más porque en el consumo reside la felicidad.

La segunda razón es que muy probablemente los cambios que se dan adentro de los bastiones del capitalismo, allí de donde emana su fuerza y su poder, lo debilitan más que los cambios en la periferia.

La tercera es que en estos momentos en que hay un control neoliberal casi total del mundo, los movimientos de los intersticios pueden escapar a ese control y ser una vía "revolucionaria" posible hacia la sustentabilidad. Según Bellamy y Magdoff, eso justamente se está dando en América Latina. Pero lo nuevo, reiteramos, es que ahora esos movimientos contra la lógica del capital están teniendo fuerza dentro del corazón mismo del sistema. Eso puede llevar a un debilitamiento nuevo y diferente del capitalismo. Como nos recuerda Burch, se ha llamado a la sencillez voluntaria "la insurrección no violenta" (2000: 176). Actualmente el sistema capitalista:

... está sofisticadamente diseñado para lidiar ferozmente con la oposición violenta... (El sistema) ve la violencia potencial en todo $y$ en todas partes, $y$ está siempre preparado para lidiar con ella. Vive en el perpetuo temor de esa violencia y la considera ineludible. Es mucho más difícil para el sistema bregar con personas que silenciosamente se alzan de hombros $y$ dicen 'ya no creemos en ustedes' (Burch, 2000: 176). 
Burch tiene razón, y en ello reside la fuerza de los movimientos de los intersticios en general, $y$ en particular la de los movimientos de los intersticios dentro de las sociedades desarrolladas, dentro de los bastiones mismos del sistema económico e ideológico. Este sistema capitalista tan fuerte y global tiene un punto muy débil: depende totalmente del consumo de las personas. Y como dice Burch (2000), el capitalismo puede seducirnos, manipularnos, lavarnos el cerebro, amenazarnos, encarcelarnos, matarnos. Pero no puede obligarnos a consumir.

\section{BIBLIOGRAFÍA}

Bellamy Foster, John. "What every environmentalist should know about capitalism". Monthly Review 61. New York. March 2010: 1-29.

Bellamy Foster, John. "Organizing Ecological Revolution”. Monthly Review 57. Issue 5. New York. October 2005:1-10.

Braidoti, Rosi. Nomadic Subjects. New York: Columbia University Press, 1994.

Burch, Mark A. Stepping Lightly: simplicity for people and the planet. British Columbia: New Society Publishers, 2000.

Cantarella, Eva (1991). La calamidad ambigua: condición e imagen de la mujer en la antigüedad griega y romana. Madrid: Ediciones Clásicas, 1996.

Epicurus. Letters, Principal Doctrines and Vatican Sayins. USA: The Library of Liberal Arts, The Bobs Merril Co. Inc. 1964.

Farrington, Benjamin (1965). Ciencia y política en el mundo antiguo. Madrid: Editorial Ayuso, 1973.
Forbes, Peter. The great remembering. San Francisco: The Trust for Public Land, 2001.

García Gual, Carlos y Acosta Méndez, Eduardo. Ética de Epicuro. Barcelona: Barral Editores, 1974.

Goodman, Amy. "Otro mundo es posible, otro Detroit se está construyendo". Democracy Now. Publicado el 17 de junio de 2010. En: <http://www. democracynow.org/blog/2010/6/23/ another_world_is_possible_another_ detroit_is_happening $>$ [Accesado el 10 de julio de 2010].

Haraway, Donna. "Situated knowledges: the science question in feminism and the privilege of partial perspective". Feminist Studies 14. Fall 1988: 575-599.

Herrera, Bernal. "Cultura y contracultura: observaciones periféricas". Realidad, Revista de Ciencias Sociales $y$ Humanidades de la UCA 108. El Salvador. Abril-junio 2006. En: <http://www. uca.edu.sv/deptos/letras/encuentro/ memorias/1culturaycontracultura.pdf> [Bajado el 15 de julio de 2010].

Iamblichus. On the Pythagorean Life. Liverpool: Liverpool University Press, 1989.

Jamblique. Protreptique. Paris: Les Belles Lettres, 1989.

Lambropoulou, Voula. "Some Pythagorean female virtues". Barbara Levick et ál. (eds). Women in Antiquity: new assessments. London: Routledge, 1995.

Ollman, Bertell. "The Utopian vision of the Future (Then and Now)". Monthly 
Review 57. Issue 3. New York. Julyaugust 2005: 78-102.

Riechman, Jorge. Biomímesis: ensayos sobre imitación de la naturaleza, ecosocialismo y autocontención. Madrid: Libros de la Catarata, 2006.

Tito Lucrecio Caro. De la naturaleza. México: Editorial Porrúa, 1985. 
